\title{
Effect of Non-Thermal Dielectric Barrier Discharge Plasma on Decontamination of Cumin Seeds
}

\author{
Rashmin M. Dhingani*, Bhavesh H. Joshi, R. V. Prasad and Akhtar Saiyad
}

Department of Food Quality Assurance, College of Food Processing Technology \& BioEnergy, Anand Agricultural University, Anand, Gujarat, India

*Corresponding author

\section{A B S T R A C T}

\begin{tabular}{|l|}
\hline Key w o r d s \\
$\begin{array}{l}\text { Decontamination, } \\
\text { Dielectric Barrier } \\
\text { Discharge, Cumin } \\
\text { seeds, Bacteria }\end{array}$ \\
\hline Article Info \\
\hline $\begin{array}{l}\text { Accepted: } \\
\text { 15 September } 2020 \\
\text { Available Online: } \\
\text { 10 October } 2020\end{array}$ \\
\hline
\end{tabular}

Keywords

Decontamination, Dielectric Barrier Discharge, Cumin

\section{Introduction}

Spices bring a world of aromas, flavors and colors to food, are widely used in different cuisines. It also delivers digestion stimulating action, antioxidant potential, hypolipidemic effect, antidiabetic influence, antiinflammatory properties, antimutagenic and anticarcinogenic potential (Rajamani et al., 2005; Srinivasan, 2005). Cumin seed (Cuminumcyminum L.) is one of the most valuable and widely used spices, because of its unique flavors, aroma, and therapeutic and medicinal properties (Mathew, 2005). It contains fats, proteins and various vitamins including thiamin, pyridoxine, riboflavin, folate, niacin, etc. Along with this, important functional component present in cumin is cuminaldehyde. Different important pharmacological properties of the essential oil of the cumin have been exploited like antimicrobial activity (Hanafy and Hatem 1991), antioxidant activity (Burits and Bucar 2000), and antitumor effect (Salomi and others 1992). Cumin seeds can be contaminated with the pathogenic bacteria such as Escherichia coli, Salmonella, Clostridium perfringens, and Bacillus cereus, 
potentially creating a public health risk and problems during transportation (Al-Jassir, 1992; Banerjee, 2003).Therefore, several decontamination technologies have been developed to reduce microbial loads of from the surface of the spices. Ethylene oxide has been proven to considerably reduce the microbial population (Toofanian and Stegeman, 1988). However, apart from aroma and color alterations, volatile compounds are lost because of the low pressure that is necessary to remove the sanitizing agent; furthermore, ethylene oxide is generally considered a carcinogen and mutagen, (Farkas and Adrassy, 1988; Vajdi and Pereira, 1973). Irradiation, including the application of gamma rays, electron beam and X-rays, is an effective method for spice decontamination (Nieto-Sandoval, Almela, Fernandez-Lopez, and Munoz, 2000). Even though ionizing radiation has proven to be an environmentally clean, and energy effective method, it is rarely used because of its poor consumer acceptance. Moreover, modifications in antioxidative properties and sensorial have been observed and it may cause the formation of low-molecular-weight non-volatile or volatile radiolysis products originating from the packaging material (Goulas, Riganakos, and Konotminas, 2004).

High hydrostatic pressure is also one of the popular non-thermal decontamination technologies. In this method pressure ranging from 100 to $1000 \mathrm{MPa}$ provides microbiologically safe and shelf-stable fruits and vegetable products (Guerrero-Beltran, Barbosa-Canovas, and Swanson, 2005; Manas and Pagan, 2005). But, the inactivation of microorganisms is strongly dependent on water activity. Spice samples with water activities below 0.66 showed less reduction in the microbial count (Butz, Heinisch, and Tauscher, 1994). Therefore, high-pressure treatment is an unsuitable sanitation method in spice production.
Numerous sterilization methods have been used for the decontamination of different food products. All the decontamination methods can be categorized into two types based on the process operate at a specific temperature that is the thermal and non-thermal decontamination method. Thermal methods are extensively used for sterilization or to achieve a predetermined reduction in viable microorganisms associated with a particular food product. But, the most important limiting factor of the thermal decontamination method that the nutritional and sensory characteristics of a food product can be changed as many component cannot withstand higher temperature. Thus, for the decontamination of the food product, a more promising method is the non-thermal decontamination method. It has potential applications for the decontamination of raw produce, nuts, minimally processed foods and packaging materials. Recently, it has been started to use in the decontamination of herbs, spices, seeds, and dehydrated vegetable substances without producing unwanted quality damage (Schluter, 2013). These non-thermal gas discharges comprise highly energetic plasma species including charged particles, chemically reactive metastable species, free radicals and UV photons, all of which can impart energies as high as $10 \mathrm{eV}$ and which are capable of breaking molecular bonds and are therefore lethal for microorganisms (Hermann et al., 1999; Montie et al., 2000; Laroussi and Leipold 2004).

Two classes of plasma, namely thermal and Non-thermal Plasma (NTP) can be distinguished based on conditions in which they are generated. Plasma generation at atmospheric pressure includes Corona discharge, Dielectric Barrier Discharges (DBD), Radio-frequency plasmas (RFP) and the gliding arc discharge. For deactivation of microorganisms from the air, Non-thermal atmospheric pressure is effective technology. 
The advent of electrically generating nonthermal gas plasmas at ambient conditions rather than under vacuum conditions offers a potentially new process for ensuring the microbiological safety of a range of products (Eliasson and Kogelschatz 1991). Cold sterilization techniques are already used to decontaminate a wide variety of heat-sensitive instruments and materials in modern medical practice (Moisan, 2002). It has numerous advantages over more conventional methods such as low process operational costs, short treatment time at low temperatures, nontoxic nature, significant reduction of water consumption throughout disinfection processes, and its application for a wide variety of goods (Song et al., 2009; Chiang et al., 2010; Korachi et al., 2010).

The term "plasma" refers to a partially or wholly ionized gas composed essentially of photons, ions and free electrons as well as atoms in their fundamental or excited states possessing a net neutral charge. Plasma generated at atmospheric pressure between two parallel electrodes, at least one of which is covered by a dielectric layer is called Dielectric Barrier Discharge - Atmospheric Cold Plasma. The DBD system consists of a plasma chamber containing a pair of electrodes separated by an insulating dielectric barrier. The schematic diagram of the plasma system is shown in Fig. 1. The material is fed into the plasma chamber, passes from the electrode pair at where it is exposed to the plasma (Fig. 2) and finally treated material is collected from the other end of the chamber. It has been demonstrated that DBD is an effective tool, particularly in the destruction of resistant microorganisms such as Bacillus subtilis (spores), Bacillus anthracis (anthrax spores), and Deinococcus radiodurans (microorganisms that survive strong radiation of nuclear materials). The range of applications of plasma sterilization at atmospheric pressure is wide, from medical instruments and spacecraft to different food products (Fridman, 2008).

Non-thermal plasma is a new concept in food processing technology and reports available are scanty in India. To explore this novel physical decontamination technology to increase the shelf life of farm produce, a laboratory study has been carried out using cumin seed spiked with the different bacterial cultures.

\section{Materials and Methods}

\section{Preparation of inoculums}

Bacterial pure culture (E. coli, S. typhi, E. aerogenes and $S$. aureus) were inoculated in nutrient broth and incubated at $37^{\circ} \mathrm{C}$ for $24 \mathrm{~h}$. Activated cultures were streaked onto the nutrient agar plate using a sterile wire loop and incubated at $37^{\circ} \mathrm{C}$ for $24 \mathrm{~h}$. A single colony was then transferred and inoculated in sterile liquid broth. It was then grown overnight in an incubator at $37^{\circ} \mathrm{C}$ for about 24 h.

\section{Dielectric Barrier Discharge (DBD) cold plasma treatment}

Cold plasma treatment for pure bacterial cultures: The efficacy of the DBD nonthermal plasma for pure bacterial cultures ( $E$. coli, S. typhi, E. aerogenes and S. aureus) was evaluated. Pure bacterial cultures were exposed to different plasma levels for different exposure time.

\section{Cold plasma treatment for spiked cumin seeds}

Spiked sample preparation: 5 g Cumin seeds were taken in the sterile petri plate. Activated pure cultures (E. coli/S. typhi/E. aerogenes/S. aureus) were inoculated onto the cumin seeds using a micropipette and then 
mixing was carried out by vigorously shaking of plates. The spiked samples were allowed to dry for about $15 \mathrm{~min}$ in laminar airflow. Then the spiked samples were divided into two parts, one for control and another for treatments.

Cold plasma treatment of spiked sample: The efficacy of the DBD non-thermal plasma for surface decontamination of spiked cumin seed was evaluated. Spiked cumin seeds were exposed to different plasma levels for different exposure time.

Microbial analysis: Microbiological quantification was carried out for control (plasma untreated) and test (plasma-treated) samples both for pure culture samples and spiked samples separately. Microbial enumeration was carried out through the spread plate technique after serial dilutions. Then the plates were incubated at $37^{\circ} \mathrm{C}$ for 24 $\mathrm{h}$ in an incubator. After incubation, samples were enumerated and the microbiological counts were expressed as $\log 10 \mathrm{CFU} / \mathrm{g}$. The difference between the test and control samples was represented as microbial log reduction $(\log 10 \mathrm{CFU} / \mathrm{g})$.

\section{Results and Discussion}

Effect of non-thermal DBD plasma on $E$. coli in cumin seeds: Efficacy of cold plasma on a pure culture of $E$. coli and cumin seed spiked with $E$. coli were evaluated at $2 \mathrm{kV}$, $3.5 \mathrm{kV}$ and $5 \mathrm{kV}$ for 8,16 and $24 \mathrm{~min}$ exposure time.

Maximum reduction of $3.2 \mathrm{log} \mathrm{CFU} / \mathrm{g}$ and $3.28 \mathrm{log} \mathrm{CFU} / \mathrm{g}$ was observed after $24 \mathrm{~min}$ exposure at $5 \mathrm{kV}$ in pure culture of $E$. coli and cumin seed spiked with the E. coli respectively. The effect of DBD plasma on E. coli culture as well as spiked in cumin seeds was found almost similar at $5 \mathrm{kV}$ for 24 min. The effect of DBD plasma on decontamination rate was found increasing with increasing voltage and exposure time. The effect of DBD plasma treatment on $E$. coli showed a significant reduction of around $3 \log$ (Table 1).

Table.1 Effect of DBD plasma treatment on E. coli

\begin{tabular}{|c|c|c|c|c|c|c|c|}
\hline \multirow{2}{*}{$\begin{array}{c}\text { Plasma } \\
\text { Voltage, } \\
\text { KV (V) }\end{array}$} & \multirow{2}{*}{$\begin{array}{c}\text { Exposure } \\
\text { Time, min (T) }\end{array}$} & \multicolumn{3}{|c|}{ E.coli spiked in cumin seeds } & \multicolumn{3}{|c|}{ E. coli pure culture } \\
\hline & & \multicolumn{3}{|c|}{$\begin{array}{c}\text { Log reduction } \\
(\log \mathrm{CFU} / \mathrm{g})\end{array}$} & \multicolumn{3}{|c|}{$\begin{array}{l}\text { Log reduction } \\
(\log \mathrm{CFU} / \mathrm{ml})\end{array}$} \\
\hline 2 & 8 & \multicolumn{3}{|c|}{0.89} & \multicolumn{3}{|c|}{0.25} \\
\hline 2 & 16 & \multicolumn{3}{|c|}{1.17} & \multicolumn{3}{|c|}{0.93} \\
\hline 2 & 24 & \multicolumn{3}{|c|}{1.61} & \multicolumn{3}{|c|}{1.53} \\
\hline 3.5 & 8 & \multicolumn{3}{|c|}{1.29} & \multicolumn{3}{|c|}{0.51} \\
\hline 3.5 & 16 & \multicolumn{3}{|c|}{1.70} & \multicolumn{3}{|c|}{1.07} \\
\hline 3.5 & 24 & \multicolumn{3}{|c|}{2.49} & \multicolumn{3}{|c|}{2.08} \\
\hline 5 & 8 & \multicolumn{3}{|c|}{2.26} & \multicolumn{3}{|c|}{0.69} \\
\hline 5 & 16 & \multicolumn{3}{|c|}{2.76} & \multicolumn{3}{|c|}{2.04} \\
\hline 5 & 24 & \multicolumn{3}{|c|}{3.28} & \multicolumn{3}{|c|}{3.20} \\
\hline & & $\mathbf{T}$ & V & $\mathbf{T} \times \mathbf{V}$ & $\mathbf{T}$ & V & $\mathbf{T} \times \mathbf{V}$ \\
\hline \multicolumn{2}{|r|}{ SEm } & 0.06 & 0.06 & 0.11 & 0.06 & 0.06 & 0.11 \\
\hline \multicolumn{2}{|c|}{ CD (0.05) } & 0.19 & 0.19 & 0.33 & 0.19 & 0.19 & 0.33 \\
\hline \multicolumn{2}{|r|}{ CV\% } & \multicolumn{3}{|c|}{2.26} & \multicolumn{3}{|c|}{2.37} \\
\hline
\end{tabular}


Table.2 Effect of DBD treatment on S. typhi

\begin{tabular}{|c|c|c|c|c|c|c|c|}
\hline \multirow{2}{*}{$\begin{array}{l}\text { Plasma } \\
\text { Voltage, } \\
\text { KV (V) }\end{array}$} & \multirow{2}{*}{$\begin{array}{c}\text { Exposure } \\
\text { Time, min } \\
\text { (T) }\end{array}$} & \multicolumn{3}{|c|}{ S. typhi spiked in cumin seeds } & \multicolumn{3}{|c|}{ S. typhi pure culture } \\
\hline & & \multicolumn{3}{|c|}{$\begin{array}{l}\text { Log reduction } \\
(\log \text { CFU/g) }\end{array}$} & \multicolumn{3}{|c|}{$\begin{array}{c}\text { Log reduction } \\
\text { (log CFU/ml) }\end{array}$} \\
\hline 2 & 8 & \multicolumn{3}{|c|}{0.89} & \multicolumn{3}{|c|}{0.40} \\
\hline 2 & 16 & \multicolumn{3}{|c|}{1.20} & \multicolumn{3}{|c|}{0.74} \\
\hline 2 & 24 & \multicolumn{3}{|c|}{1.49} & \multicolumn{3}{|c|}{1.05} \\
\hline 3.5 & 8 & \multicolumn{3}{|c|}{1.16} & \multicolumn{3}{|c|}{0.84} \\
\hline 3.5 & 16 & \multicolumn{3}{|c|}{1.67} & \multicolumn{3}{|c|}{1.15} \\
\hline 3.5 & 24 & \multicolumn{3}{|c|}{2.21} & \multicolumn{3}{|c|}{1.58} \\
\hline 5 & 8 & \multicolumn{3}{|c|}{2.02} & \multicolumn{3}{|c|}{1.13} \\
\hline 5 & 16 & \multicolumn{3}{|c|}{2.71} & \multicolumn{3}{|c|}{1.71} \\
\hline 5 & 24 & \multicolumn{3}{|c|}{3.30} & \multicolumn{3}{|c|}{2.25} \\
\hline & & $\mathbf{T}$ & $\mathbf{V}$ & $\mathbf{T} \times \mathbf{V}$ & $\mathbf{T}$ & $\mathbf{V}$ & $\mathbf{T} \times \mathbf{V}$ \\
\hline \multicolumn{2}{|c|}{ SEm } & 0.08 & 0.08 & 0.15 & 0.07 & 0.07 & 0.12 \\
\hline \multicolumn{2}{|c|}{ CD (0.05) } & 0.26 & 0.26 & NS & 0.20 & 0.20 & 0.41 \\
\hline \multicolumn{2}{|c|}{ CV\% } & \multicolumn{3}{|c|}{4.46} & \multicolumn{3}{|c|}{2.48} \\
\hline
\end{tabular}

Table.3 Effect of DBD treatment on E. aerogenes

\begin{tabular}{|c|c|c|c|c|c|c|c|}
\hline \multirow{2}{*}{$\begin{array}{c}\text { Plasma } \\
\text { Voltage, } \\
\text { V (V) }\end{array}$} & \multirow{2}{*}{$\begin{array}{c}\text { Exposure } \\
\text { Time, min } \\
\text { (T) }\end{array}$} & \multicolumn{3}{|c|}{$\begin{array}{c}\begin{array}{c}\text { E. aerogenes spiked in cumin } \\
\text { seeds }\end{array}\end{array}$} & \multicolumn{3}{|c|}{ E. aerogenes pure culture } \\
\hline & & \multicolumn{3}{|c|}{$\begin{array}{l}\text { Log reduction } \\
(\log \text { CFU/g) }\end{array}$} & \multicolumn{3}{|c|}{$\begin{array}{c}\text { Log reduction } \\
(\log \text { CFU/ml) }\end{array}$} \\
\hline 2 & 8 & \multicolumn{3}{|c|}{0.81} & \multicolumn{3}{|c|}{0.28} \\
\hline 2 & 16 & \multicolumn{3}{|c|}{1.09} & \multicolumn{3}{|c|}{0.59} \\
\hline 2 & 24 & \multicolumn{3}{|c|}{1.32} & \multicolumn{3}{|c|}{0.92} \\
\hline 3.5 & 8 & \multicolumn{3}{|c|}{1.05} & \multicolumn{3}{|c|}{0.43} \\
\hline 3.5 & 16 & \multicolumn{3}{|c|}{1.52} & \multicolumn{3}{|c|}{0.94} \\
\hline 3.5 & 24 & \multicolumn{3}{|c|}{1.90} & \multicolumn{3}{|c|}{1.35} \\
\hline 5 & 8 & \multicolumn{3}{|c|}{1.32} & \multicolumn{3}{|c|}{0.64} \\
\hline 5 & 16 & \multicolumn{3}{|c|}{1.87} & \multicolumn{3}{|c|}{1.99} \\
\hline 5 & 24 & \multicolumn{3}{|c|}{2.28} & \multicolumn{3}{|c|}{3.12} \\
\hline & & $\mathbf{T}$ & $\mathbf{V}$ & $\mathbf{T} \times \mathbf{V}$ & $\mathbf{T}$ & $\mathbf{V}$ & $\mathbf{T} \times \mathbf{V}$ \\
\hline \multicolumn{2}{|c|}{ SEm } & 0.05 & 0.05 & 0.10 & 0.05 & 0.05 & 0.10 \\
\hline \multicolumn{2}{|c|}{ CD (0.05) } & 0.17 & 0.17 & NS & \multirow{2}{*}{\multicolumn{3}{|c|}{2.14}} \\
\hline \multicolumn{2}{|c|}{ CV\% } & \multicolumn{3}{|c|}{2.30} & & & \\
\hline
\end{tabular}


Table.4 Effect of DBD treatment on S. aureus

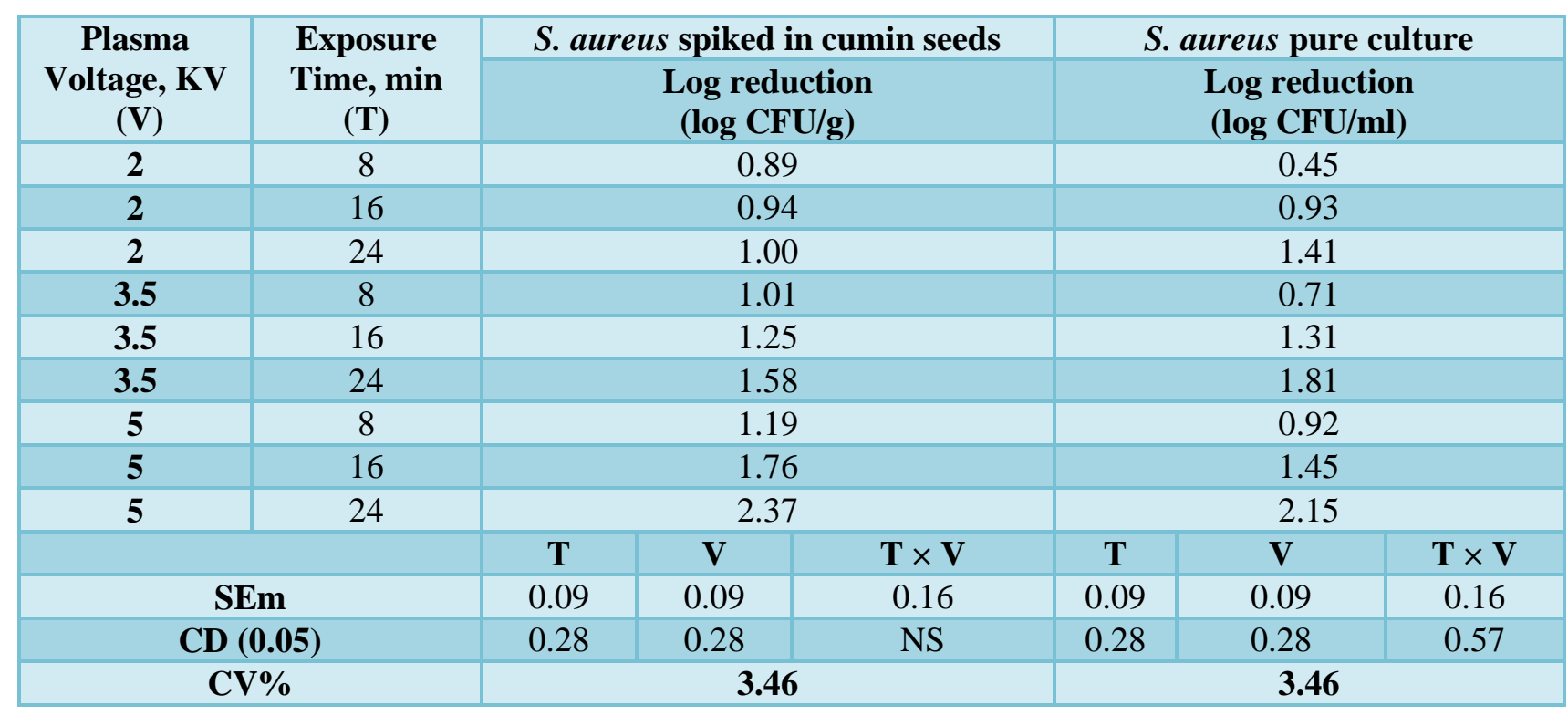

Fig.1 Schematic diagram of DBD plasma system

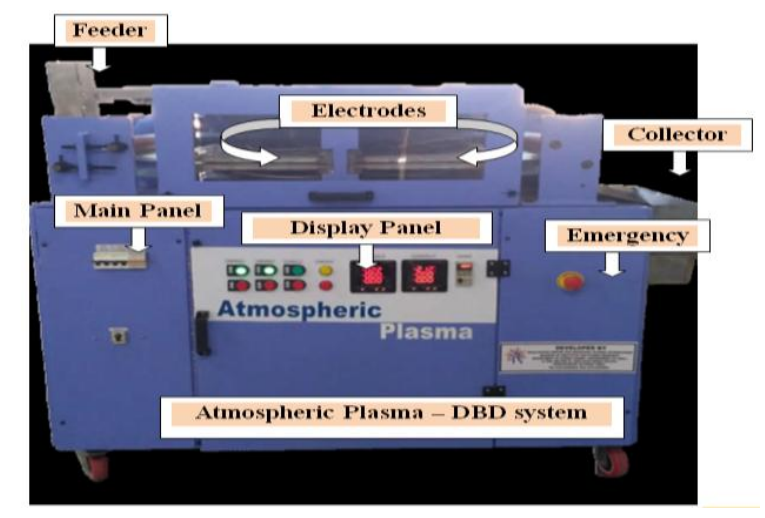

Fig.2 Cold plasma generations between two electrodes
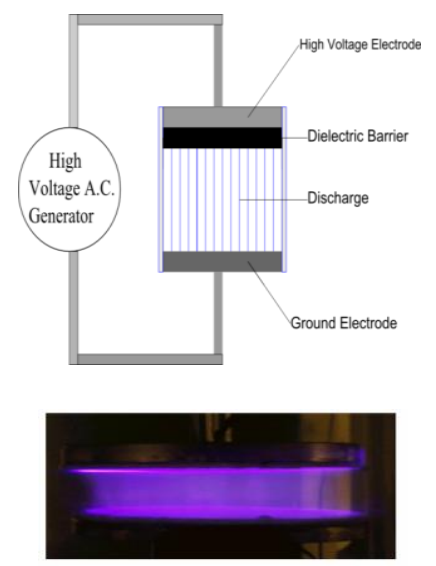


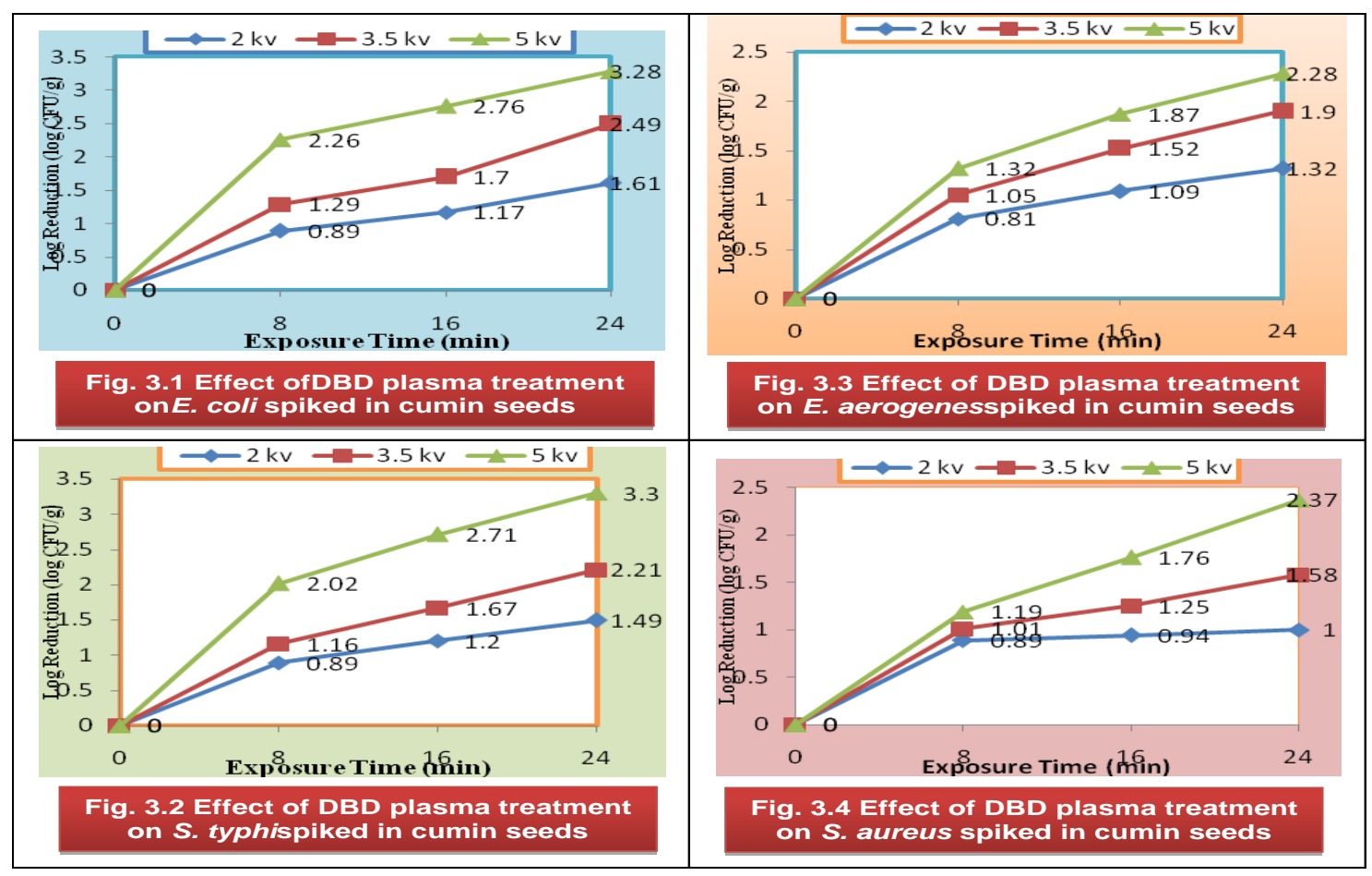

Effect of Non-Thermal DBD Plasma on $S$. typhi in cumin seeds: Efficacy of cold plasma on a pure culture of $S$. typhi and cumin seed spiked with $S$. typhi were evaluated at $2 \mathrm{kV}, 3.5 \mathrm{kV}$ and $5 \mathrm{kV}$ for 8,16 and 24 min exposure time (Table 2).

Maximum reduction of $2.25 \mathrm{log} \mathrm{CFU} / \mathrm{g}$ and $3.30 \log \mathrm{CFU} / \mathrm{g}$ was observed after $24 \mathrm{~min}$ exposure at $5 \mathrm{kV}$ in pure culture of $S$. typhi and cumin seed spiked with the $S$. typhi respectively. The effect of DBD on decontamination rate was found increasing with increasing voltage and exposure time. The effect of DBD plasma treatment on $S$. typhi showed a significant reduction of around 2 - $3 \log$.

Effect of Non-Thermal DBD Plasma on $E$. aerogenes in cumin seeds: Efficacy of cold plasma on a pure culture of $E$. aerogenes and cumin seed spiked with $E$. aerogenes was evaluated at $2 \mathrm{kV}, 3.5 \mathrm{kV}$ and $5 \mathrm{kV}$ for 8,16 and 24 min exposure time (Table 3 ).
Maximum reduction of $3.12 \log \mathrm{CFU} / \mathrm{g}$ and $2.28 \log \mathrm{CFU} / \mathrm{g}$ was observed after $24 \mathrm{~min}$ exposure at $5 \mathrm{kV}$ in pure culture of $E$. aerogenes and cumin seed spiked with the $E$. aerogenes respectively. The effect of DBD plasma treatment on E. aerogenes showed significant reduction of around $2-3 \log$.

Effect of Non-Thermal DBD Plasma on $S$. aureus in cumin seeds: Efficacy of cold plasma on a pure culture of $S$. aureus and cumin seed spiked with $S$. aureus was evaluated at $2 \mathrm{kV}, 3.5 \mathrm{kV}$ and $5 \mathrm{kV}$ for 8,16 and 24 min exposure time (Table 4).

Maximum reduction of $2.15 \log \mathrm{CFU} / \mathrm{g}$ and $2.37 \log \mathrm{CFU} / \mathrm{g}$ was observed after $24 \mathrm{~min}$ exposure at $5 \mathrm{kV}$ in pure culture of $S$. aureus and cumin seed spiked with the $S$. aureus respectively. The effect of DBD plasma treatment on $S$. aureus showed a significant reduction of around $2 \log$.

In conclusion the dielectric Barrier Discharge - Atmospheric Cold Plasma (DBD-ACP) 
technology has been emerging as a promising non-thermal decontamination technology which can be used for the reduction of surface microbial load with maintaining the sensory and nutritional quality of the product. This technology is increasingly finding acceptance among food processors for surface decontamination in many countries for the fruits, vegetables and spices. The effect of cold plasma treatment on cumin seeds spiked with pure microbial culture showed that upon microbial exposure to $5 \mathrm{kV}$ cold plasma for $24 \mathrm{~min}$, around 3.3, 3.3, 2.3 and $2.4 \mathrm{log}$ reduction $(\mathrm{CFU} / \mathrm{g})$ were observed in $E$. coli, $S$. typhi, E. aerogenes and $S$. aureus respectively. Data revealed that DBD-ACP system of $5 \mathrm{kV}$ can be effectively used for the reduction of microbial load of around $2-3$ $\log$ from the surface. For more promising data more research needs to be undergone using this technology with different commodities and different microorganisms. This technology can become one of the reliable most efficient non-thermal microbial decontamination technologies in the upcoming era.

\section{Acknowledgements}

The project scientists sincerely thank for the financial support given by ICAR, New Delhi. The authors also thank the College of Food Processing Technology and Bioenergy and Anand Agricultural University for providing infrastructure and other necessary facilities. The support given by the Facilitation Center for Industrial Plasma Technologies (FCIPT) of the Institute of Plasma Research, Gandhinagar is highly appreciated for helping in designing and fabricating DBD atmospheric cold plasma system for this project.

\section{References}

Al-Jassir, M.S., 1992. Chemical composition and microflora of black cumin (Nigella sativa L.) seeds growing in Saudi Arabia. Food Chem. 45(4): 239-242.

Banerjee, M., Sarkar, P.K., 2003. Microbiological quality of some retail spices in India. Food Res Int. 36(5): 46974.

Burits, M., Bucar, F., 2000. Antioxidant activity of Nigella sativa essential oil. Phytother, Res. 14, 323-328.

Hanafy, M.S.M., Hatem, M.E., 1991. Studies on the antimicrobial activity of Nigella sativa seed (black cumin). J Ethnopharmacol. 34, 275-8.

Moisan, M., Barbeau, J., Crevier, M.C., Pelletier, J., Philip, N., Saoudi, B., 2002. Plasma sterilization: methods and mechanisms. Pure Appl Chem. 74(3): 349-358.

Fridman, G., Friedman, G., Gutsol, A., Shekhter, A.B., Vasilets, V.N., Fridman, A., 2008. Applied plasma medicine. Plasma Proc Polymers. 5(6): 503-33.

Schluter, O., Ehlbeck, J., Hertel, C., Habermeyer, M., Roth, A., Engel, K.H., Holzhauser, T., Knorr, D., 2013. Opinion on the use of plasma processes for treatment of foods. MolNutr Rood Res. 57(5): $\quad$ 920-7. doi:10.1002/mnfr.201300039.

Eliasson, B. and Kogelschatz, U., 1991. Non equilibrium volume plasma chemical processing. IEEE Trans Plasma Sci. 19, 1063-1077.

Hermann, H.W., Henins, I., Park, J. and Selwyn, G.S., 1999. Decontamination of chemical and biological warfare (CBW) agents using an atmospheric pressure plasma jet (APPJ). Phys Plasmas. 6, 2284-2289.

Montie, T.C., Kelly-Wintenberg, K. and Roth, J.R., 2000. An overview of research using the one atmosphere uniform glow discharge plasma (OAUGDP) for sterilization of surfaces and materials. IEEE Trans Plasma Sci. 28, 41-50.

Laroussi, M. and Leipold, F., 2004. Evaluation of the roles of reactive species, heat, and $\mathrm{UV}$ radiation in inactivation of bacterial cells by air plasmas at atmospheric 
pressure. Int J Mass Spectrom. 233, 8186.

Song, H.P., Kim, B., Choe, J.H., Jung, S., Moon, S.S., Choe, W. and Jo, C., 2009. Evaluation of atmospheric pressure plasma to improve the safety of sliced cheese and ham inoculated by 3 -strain cocktail Listeria monocytogenes. Food Microbiol. 26, 432-436.

Chiang, M.H., Wu, J.Y., Li, Y.H., Wu, S., Chen, S.H. and Chang, C.L., 2010. Inactivation of E. coli and B. subtilis by a parallel-plate dielectric barrier discharge jet. Surf Coat Technol. 204, 3729-3737.

Korachi, M., Gurol, C. and Aslan, N., 2010. Atmospheric plasma discharge sterilization effects on whole cell fatty acids profile of Escherichia coli and Staphylococcus aureus. J Electrostat. 68, 508-512.

Rajamani, S., Suganthi, R., Ravichandran, M.K., Anuradha, C.V., 2005. Food seasoning spices mixture improves glucose metabolism and lipid profile in fructose-fed hyper insulinemic rats. JMed Food. 8, 502-7.

Salomi, N.J., Nair, S.C., Jayawardhanan, K.K., Varghese, C.D., Panikkar, K.R., 1992. Antitumour principles from Nigella sativa seeds. Cancer Lett. 6, 41-6.

Srinivasan, K., 2005. Role of spices beyond food flavoring: Nutraceuticals with multiple health effects. Food Rev Int. 21, 167-88.

Toofanian, F., and Stegeman, H., 1988. Comparative effect of ethylene oxide and gamma irradiation on the chemical sensory and microbial quality of ginger, cinnamon, fennel and fenugreek. Acta
Alimentaria. 17, 271-281.

Farkas, J., and Adrassy, E., 1988. Comparative analysis of spices decontaminated by ethylene oxide or gamma irradiation. Acta Alimentaria. 17, 77-94.

Vajdi, M., and Pereira, R. R., 1973. Comparative effects of ethylene oxide, gamma irradiation and microwave treatments on selected spices. Journal of Food Science. 38, 893-895.

Nieto-Sandoval, J.M., Almela, L., FernandezLopez, J.A., and Munoz, J.A., 2000. Effect of electron beam irradiation on color and microbial bioburden of red paprika. Journal of Food Protection. 63, 633-637.

Goulas, A.E., Riganakos, K.A., and Konotminas, M.G., 2004. Effect of ionizing radiation on physicochemical and mechanical properties of commercial monolayer and multilayer semi rigid plastics packaging materials. Radiation Physics and Chemistry. 69, 411-417.

Guerrero-Beltran, J., Barbosa-Canovas, G., and Swanson, B., 2005. High hydrostatic pressure processing of fruit and vegetable products. Food Reviews International. 21, 411-425.

Manas, P., and Pagan, R., 2005. Microbial inactivation by new technologies of food preservation. Journal of Applied Microbiology. 98, 1387-1399.

Butz, P., Heinisch, O., and Tauscher, B., 1994. Hydrostatic high pressure applied to food sterilization III: application to spices and spice mixtures. High Pressure Research. 12, 239-243.

\section{How to cite this article:}

Rashmin M. Dhingani, Bhavesh H. Joshi, R. V. Prasad and Akhtar Saiyad. 2020. Effect of Non-Thermal Dielectric Barrier Discharge Plasma on Decontamination of Cumin Seeds. Int.J.Curr.Microbiol.App.Sci. 9(10): 2029-2037. doi: https://doi.org/10.20546/ijcmas.2020.910.247 